\title{
Magnetic resonance imaging of the perineum in pediatric patients with inflammatory bowel disease
}

\author{
Douglas H Jamieson MBChB FFRAD(D)SA FRCPC ${ }^{2}$, Peter Shipman MBBS DipCD(PMH) FRANZCR ${ }^{5}$, \\ Kevan Jacobson MBBCh FRCPC AGAF ${ }^{1,3,4}$
}

\begin{abstract}
DH Jamieson, P Shipman, K Jacobson. Magnetic resonance imaging of the perineum in pediatric patients with inflammatory bowel disease. Can J Gastroenterol 2013;27(8):476-480.

Magnetic resonance imaging (MRI) has profoundly changed and improved the investigation of abdominal and pelvic inflammatory bowel disease (IBD) in pediatrics. Using an imaging modality without ionizing radiation is of particular advantage because the pediatric IBD population is young and often requires repeat evaluation. MRI of the pelvis has become the imaging gold standard for detecting and monitoring perianal disease while bowel-directed imaging techniques (eg, enterography, enteroclysis and colonography) can accurately evaluate bowel inflammation in IBD. With recent technological innovations leading to faster and higher resolution, the role of MRI in IBD will likely continue to expand. The present article focuses on MRI of the perineum in pediatric IBD.
\end{abstract}

Key Words: Crohn disease; Inflammatory bowel disease; MRE; MRI; Pediatrics; Perianal disease

$\mathrm{H}$ istorically, the imaging reference standards for inflammatory bowel disease (IBD) evaluation of the small bowel were small bowel follow through or enteroclysis. This imaging modality, which relied primarily on visualization of abnormalities in the intestinal mucosal pattern and calibre, was replaced by computed tomography (CT) of the abdomen due to widespread availability, fast scanning times and highquality, high-resolution three-dimensional images of the abdomen and pelvis identifying both luminal and extraluminal disease. Nevertheless, increased access to magnetic resonance imaging (MRI), the advent of faster and higher resolution scanners, which elegantly depict the radiographic features of IBD $(1,2)$, together with the advantage of being an imaging modality without ionizing radiation (3), has made this the imaging gold standard for detection of luminal and extraluminal inflammatory disease in many institutions, including our own.

Historically, MRI of the abdomen was limited by long acquisition times and extensive motion artefact from respiration. The soft tissue contrast of MRI is superior to CT for delineation of the anal sphincter and the pelvis can be imaged in multiple planes with little image degradation from respiratory motion (4). With technological advances and the development of MRI pulse sequences that provide motiona reality (5).

MRI features of IBD include bowel wall thickening, bowel wall enhancement, fibrofatty proliferation, increased vascularity, bowel dilation and associated lymphadenopathy (Figure 1) (1,2). MRI also elegantly evaluates the abdominal extraluminal complications of IBD (Figure 2).

The presence of perineal disease in pediatric Crohn disease at diagnosis is quite variable; up to $25 \%$ will present with perineal disease at diagnosis and up to $45 \%$ will manifest with perineal complications at free, high-resolution images of the body, MRI of the bowel has become

\section{L'imagerie par résonance magnétique du périnée chez les patients d'âge pédiatrique atteints d'une maladie inflammatoire de l'intestin}

L'imagerie par résonance magnétique (IRM) a profondément changé et amélioré les examens des maladies inflammatoires de l'intestin (MII) abdominales et pelviennes en pédiatrie. Il est particulièrement avantageux d'utiliser une modalité d'imagerie sans radiation ionisante parce que la population pédiatrique atteinte d'une MII est jeune et a souvent besoin d'évaluations répétées. L'IRM du bassin est devenue la norme pour déceler et surveiller les maladies périanales, tandis que les techniques d'imagerie orientées vers les intestins (p. ex., entérographie, entéroclyse, colonographie) permettent d'évaluer avec précision l'inflammation intestinale des MII. Compte tenu des innovations technologiques récentes assurant une résolution de meilleure qualité plus rapidement, l'IRM jour a probablement un rôle de plus en plus important dans les MII. Le présent article porte sur l'IRM du périnée chez les patients d'âge pédiatrique atteints d'une MII.

some stage during the disease course (6-8). The application of MRI to the imaging of perineal complications of IBD has been highly successful (9-11). As noted, the problems of intestinal peristalsis, aortic pulsation and respiratory movement degrading bowel imaging are greatly reduced in the perineal area, and longer, higher-resolution imaging sequences can be used to provide excellent anatomical information.

MRI enables accurate delineation of fistula tract and abscess location. MRI elegantly depicts the complex sphincteric and muscle anatomy of the anal canal and perineum, which enables reference for anatomical description of fistulas and abscess location (12). This is extremely important because operative planning based on MRI findings has been shown to significantly reduce fistula recurrence (13).

\section{TECHNIQUE}

At our institution, the perineum is imaged with high-resolution, spin echo T2 sequences in the axial, coronal and sagittal planes. Application of fat saturation may increase noise but also increases pathological conspicuity. A precontrast axial fat-saturated spin echo T1 sequence is obtained and, following intravenous gadolinium contrast enhancement, axial, coronal and sagittal fat-saturated spin echo T1 sequences are acquired.

ANATOMY
The anal canal extends from the anal verge up to the upper border of
the puborectalis muscle. Two overlapping muscular cylinders surround
the anal canal. The upper, inner cylinder consists of involuntary
smooth muscle that forms the internal anal sphincter. The outer, lower
cylinder extends to the anal verge and is voluntary striated muscle
forming the external sphincter. The upper border of the external
sphincter merges with the inferior fibres of the puborectalis muscle,

${ }^{1}$ Division of Gastroenterology, Hepatology and Nutrition and ${ }^{2}$ Department of Radiology, BC Children's Hospital, ${ }^{3}$ Child and Family Research Institute,

${ }^{4}$ Department of Cellular and Physiological Sciences, University of British Columbia, Vancouver, British Columbia; ${ }^{5}$ Princess Margaret Children's

Hospital, Perth, Australia

Correspondence: Dr Kevan Jacobson and Dr Douglas Jamieson, Division of Gastroenterology, Hepatology and Nutrition and Department of Radiology,

BC Children's Hospital, 4480 Oak Street, Vancouver, British Columbia V6H 3V4. Telephone 604-875-2332, fax 604-875-3244,

e-mail kjacobson@cw.bc.ca,djamieson@cw.bc.ca

Received for publication March 1, 2013. Accepted May 6, 2013 


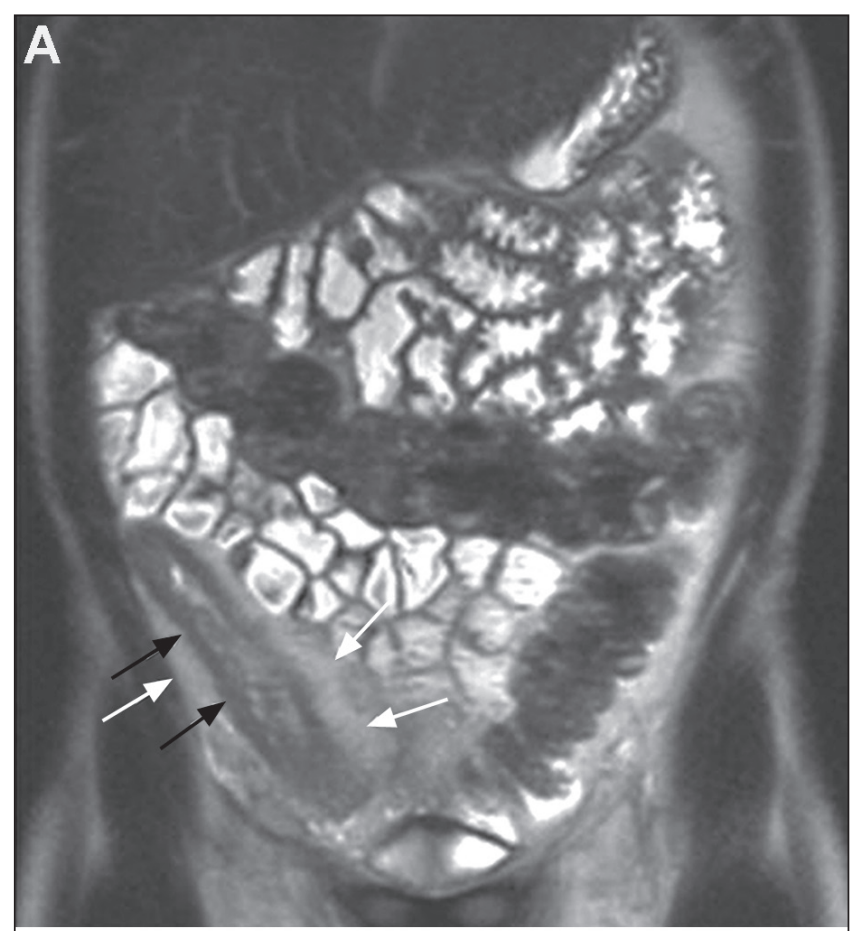

$\mathbf{B}$
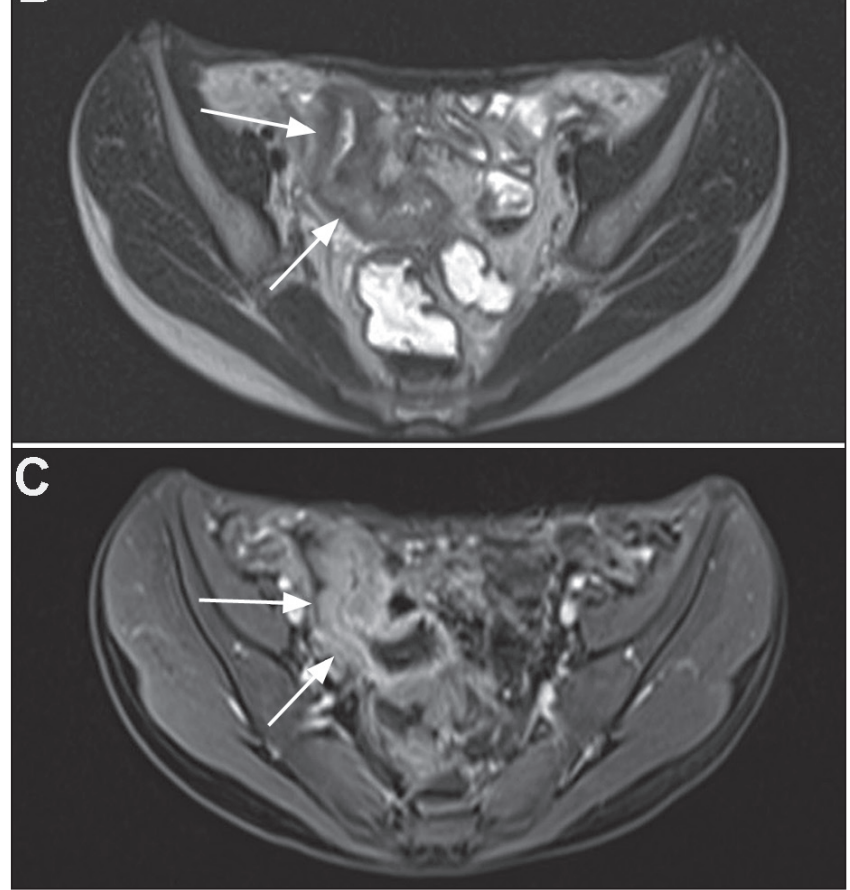

Figure 1) A Coronal T2 half-Fourier acquisition single-shot turbo spinecho (HASTE) image showing colonic and particular terminal ileal disease with bowel wall thickening (black arrows) and fibrofatty proliferation (white arrows). B Axial T2 HASTE image showing striking distal ileal bowel wall thickening (arrows). C Contrast-enhanced volumetric interpolated breathhold sequence showing enhancement of the thickened bowel wall (arrows)

which forms a sling passing behind the anal canal with attachment to the symphysis pubis anteriorly and maintains the anorectal angle. The levator ani muscles form the diaphragm-like muscular pelvic floor with posterior attachment to the anococcygeal ligament, anterior attachment to the urogenital diaphragm and lateral attachment to the pubic ramus, obturator fascia and inferior ischium. Where the anal canal passes through the levator ani, its muscle may be confluent with the upper border of puborectalis (Figure 3).
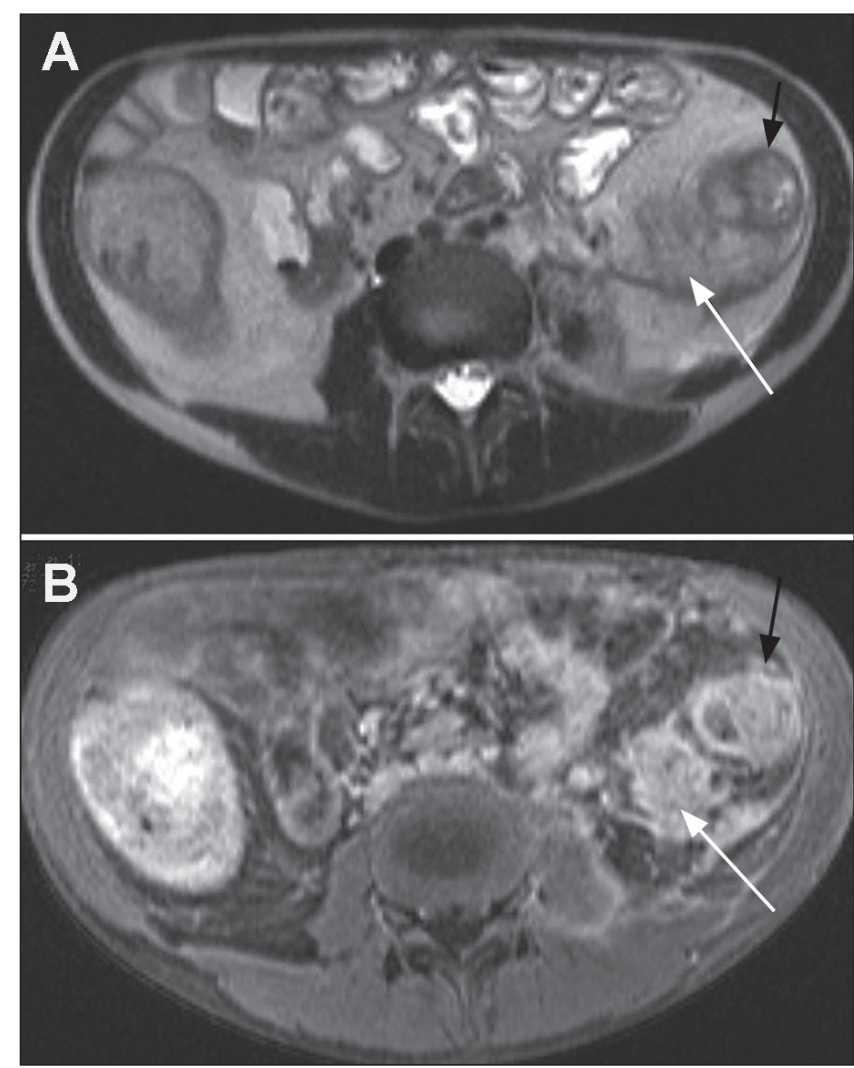

Figure 2) A Axial T2 half-Fourier acquisition single-shot turbo spin-echo (HASTE) image demonstrating abnormal descending colon (black arrow) and extensive retroperitoneal inflammatory process (white arrow). B Axial contrast-enhanced volumetric interpolated breath-hold examination image showing enhancement of thickened descending colon wall (black arrow) and diffuse enhancement of the retroperitoneal inflammation (white arrow) suggesting phlegmon rather than abscess that would rim enhance around any pus collection

The dentate line lies $2 \mathrm{~cm}$ proximal to the anal verge and is the location of the anal glands. It is these glands that, when infected, initiate the formation of anal fistulas. It is believed that enlarged lymphoid tissue around these glands in IBD predisposes to such infection (11).

Named spaces between the muscles may contain and direct fistula extension. The levator ani separates the fat of the superior 'ischio rectal' space from the inferior 'ischio anal' space. The potential intersphincteric space lies between the overlapping muscle sphincter cylinders. There is also a potential space between the inferior levator ani muscle and the upper fibres of the puborectalis known as the space of Courtney.

\section{Fistulas}

Fistulas are classified according to their anatomical course starting where they originate from the bowel lumen and describing their course to skin exit. The site of origin, length, anatomical planes through which it courses and site of exit of the fistula track are important to record to aid in treatment and surgical planning. Identifying the time clock position of the fistula with respect to the anal canal is usual in the surgical literature. Intersphincteric fistulas track down between the cylinders of the internal and external muscular sphincters and exit at the anal verge (Figure 4). Trans-sphincteric fistulas traverse through the internal and external sphincteric cylinders and usually exit further away from the anal margin (Figure 5). Internal fistulas are tracks that extend from the intestine to internal structures such as vagina, vulva and urethra (Figure 6). Fistula tracks can be multiple and delineating each can be essential to planning any surgery (Figure 7). 

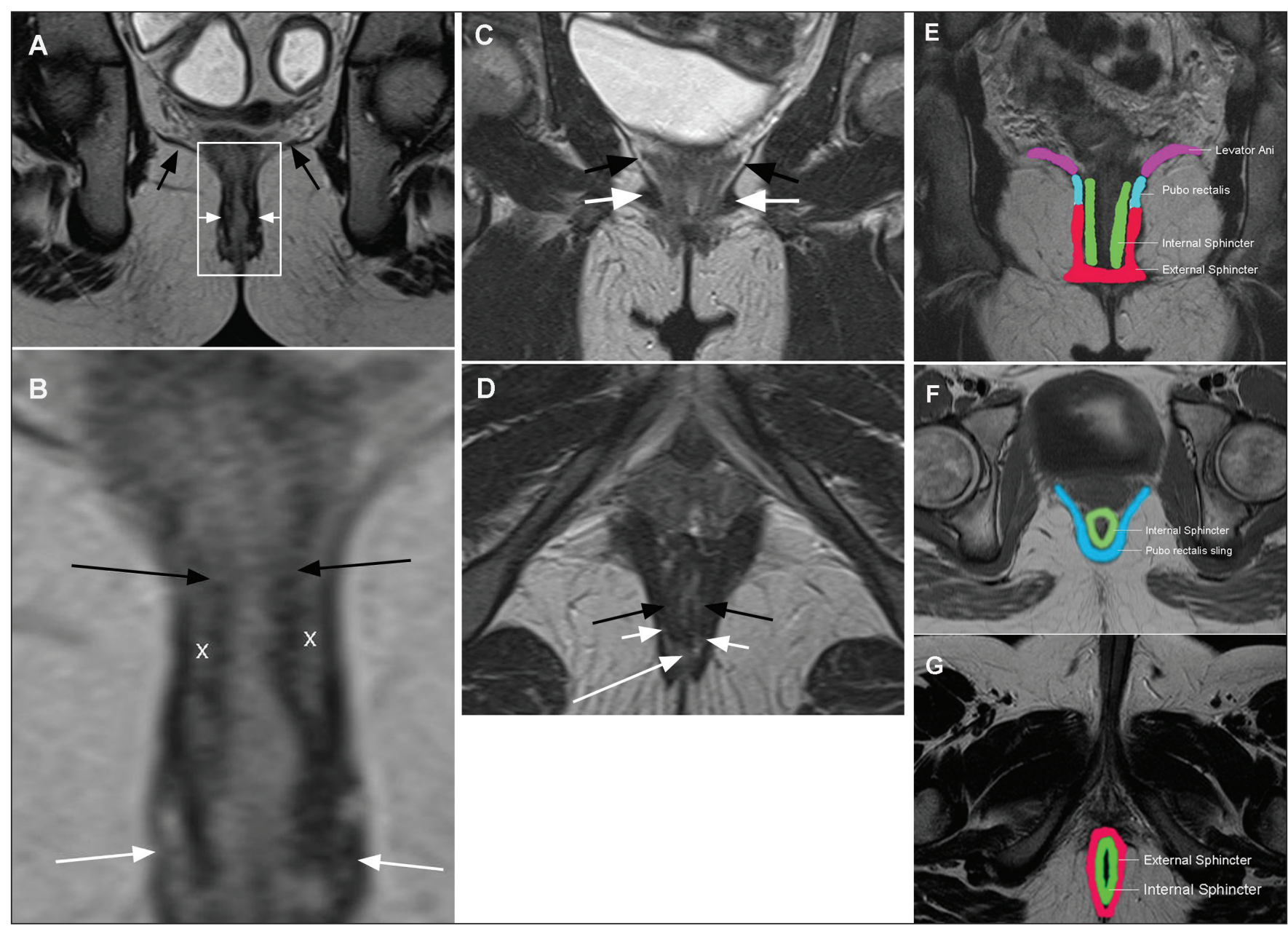

Figure 3) A Coronal image of the perineum showing the levator ani muscle (black arrows) dividing the upper ischiorectal space from the lower ischio anal space. The white rectangle delineates the anal canal and anal sphincters (white arrows), enlarged in Figure 3B. B Enlarged coronal view of the anal canal indicating the upper inner involuntary smooth muscle-internal sphincter (black arrows) and the lower outer voluntary striated muscle-external sphincter (white arrows); 'X' marks the inter-sphincteric space. C Coronal perineal image showing levator ani muscle (black arrows) and the pubo rectalis muscle (white arrows). D Axial image indicating internal sphincter (black arrows), external sphincter (short white arrows) and the posterior horseshoe-shaped space of Courtney (long white arrow). E Graphic coronal image of anatomical muscle location. F Graphic upper axial image showing in particular the sling of the puborectalis. G Graphic lower axial image of anal sphincter muscle relationship

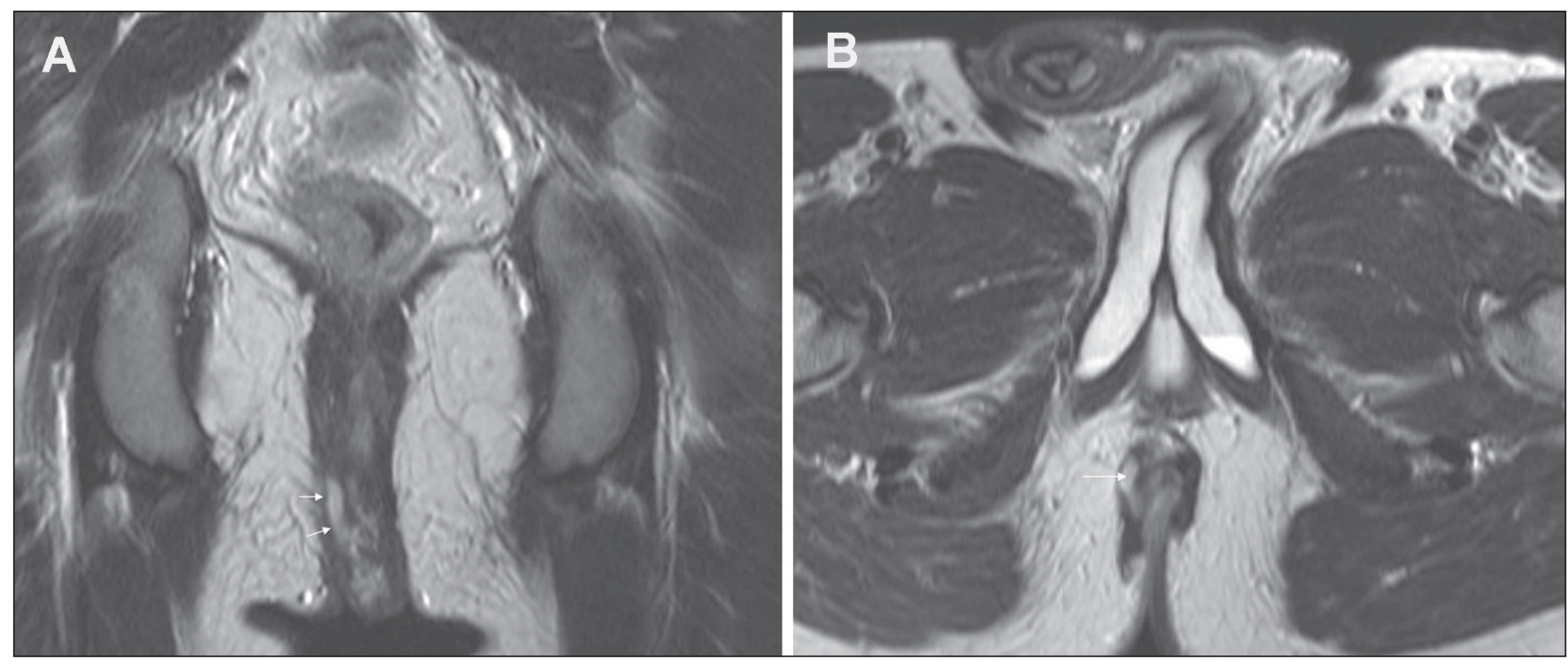

Figure 4) A Coronal T2 image demonstrating an intersphincteric fistula with fluid-filled (T2 bright) fistula (arrows) between the internal and external sphincteric muscles. B Axial T2 image showing the intersphincteric fisula (arrow) 

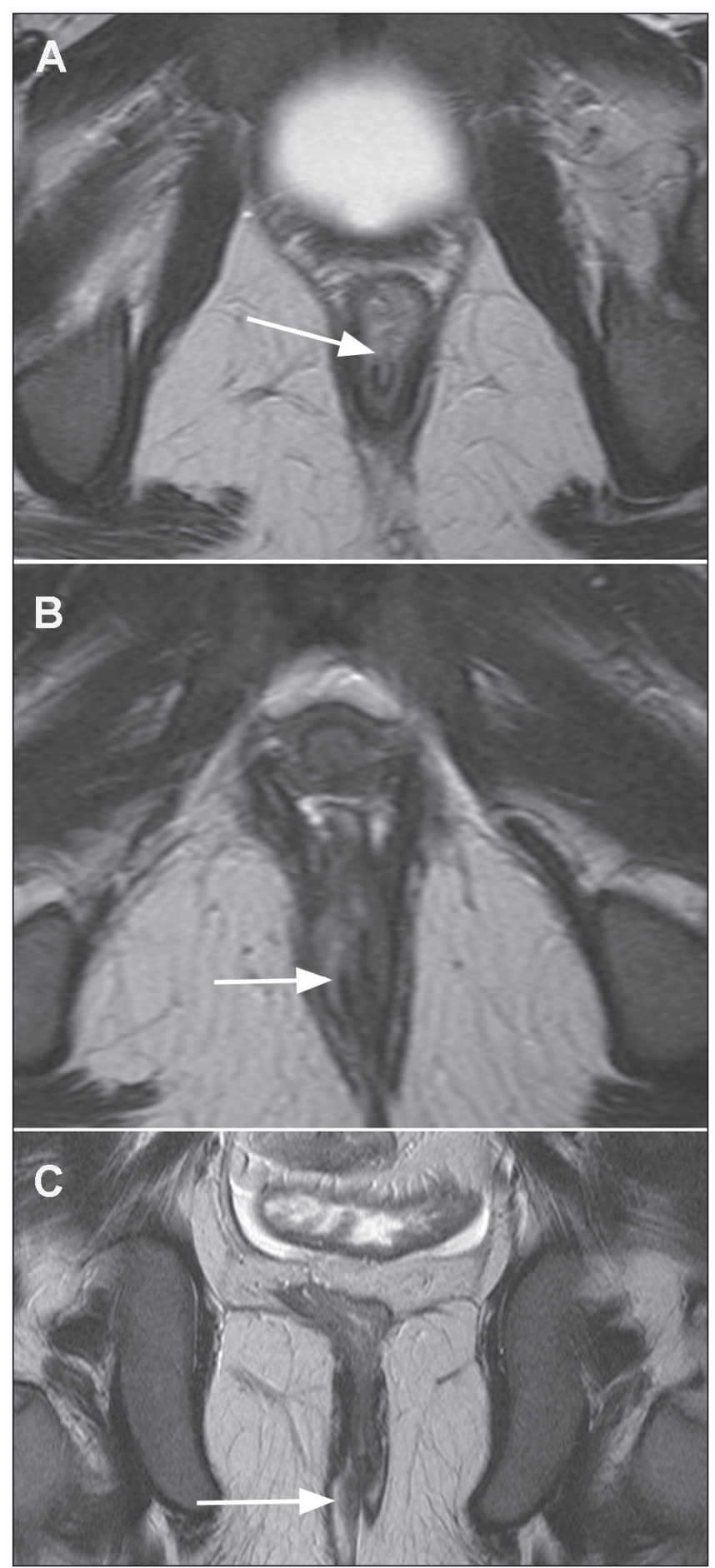

Figure 5) A Upper axial T2 image demonstrating the start of the fistula breaching the internal sphincter at 12:00 (arrow). B Mid axial T2 image demonstrating the fistula between internal and external sphincters (arrow). $\mathrm{C}$ Coronal T2 image demonstrates inferior extent of the trans-sphincteric fistula breaching through the external sphincteric muscles (arrow)

\section{Abscess}

MRI invariably delineates the sinus track from the bowel to an abscess cavity. Most perineal abscess collections are anatomically separated by the levator ani muscle. An abscess below the levator ani muscle is known as an ischio anal abscess (Figure 8). An abscess above the levator ani muscle is known as an ischiorectal abscess with the collection contained in the ischiorectal space (Figure 9). Occasionally, abscesses

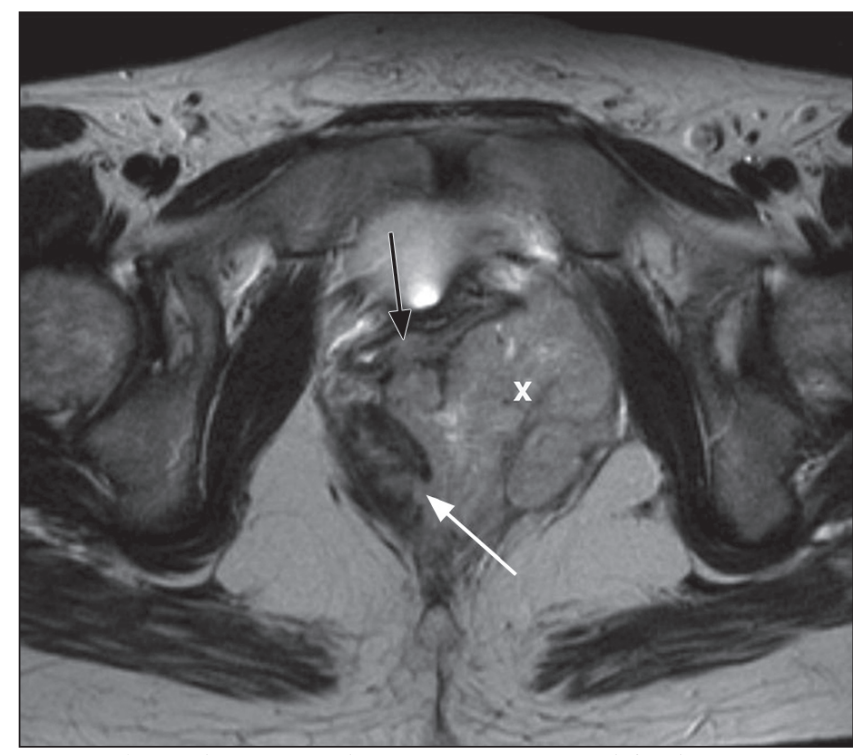

Figure 6) Axial T2 image demonstrates an internal fistula originating at 04:00 (white arrow) into an inflammatory mass ('X') and extending into the vagina anteriorly (black arrow)

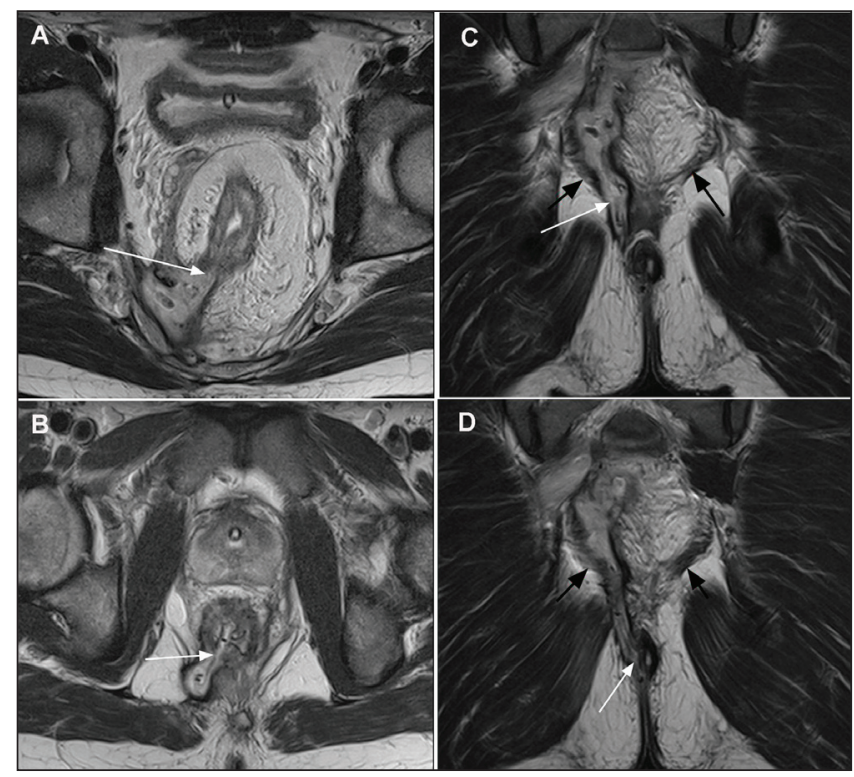

Figure 7) A Upper axial T2 image shows fistula at 07:00 (arrow). B Lower axial T2 image shows a second fistula also at 07:00 (arrow). C Coronal image demonstrates vertical extent of fistula breaching (white arrow) the left levator ani muscle (black arrows). D Coronal image demonstrates the fistula exit at the anal verge; clinical inspection may have indicated an intersphincteric fistula. Magnetic resonance imaging elegantly displayed the full complex fistula anatomy

can then traverse the levator ani muscle involving both compartments. A sinus tracking to the space of Courtney can result in an abscess developing in this space, forming a 'horseshoe' abscess. The delineation of the abscess collection and sinus has important consequences for any surgical approach to drainage or seton placement.

The accurate evaluation of the anatomical location of fistula tracks, sinus and abscess cavity is important for planning therapy including surgical treatment. Accurate presurgical information has improved long-term outcomes in this population. A $75 \%$ reduction in postsurgical recurrence rates have been reported when operative planning has been based on MRI findings (13). 

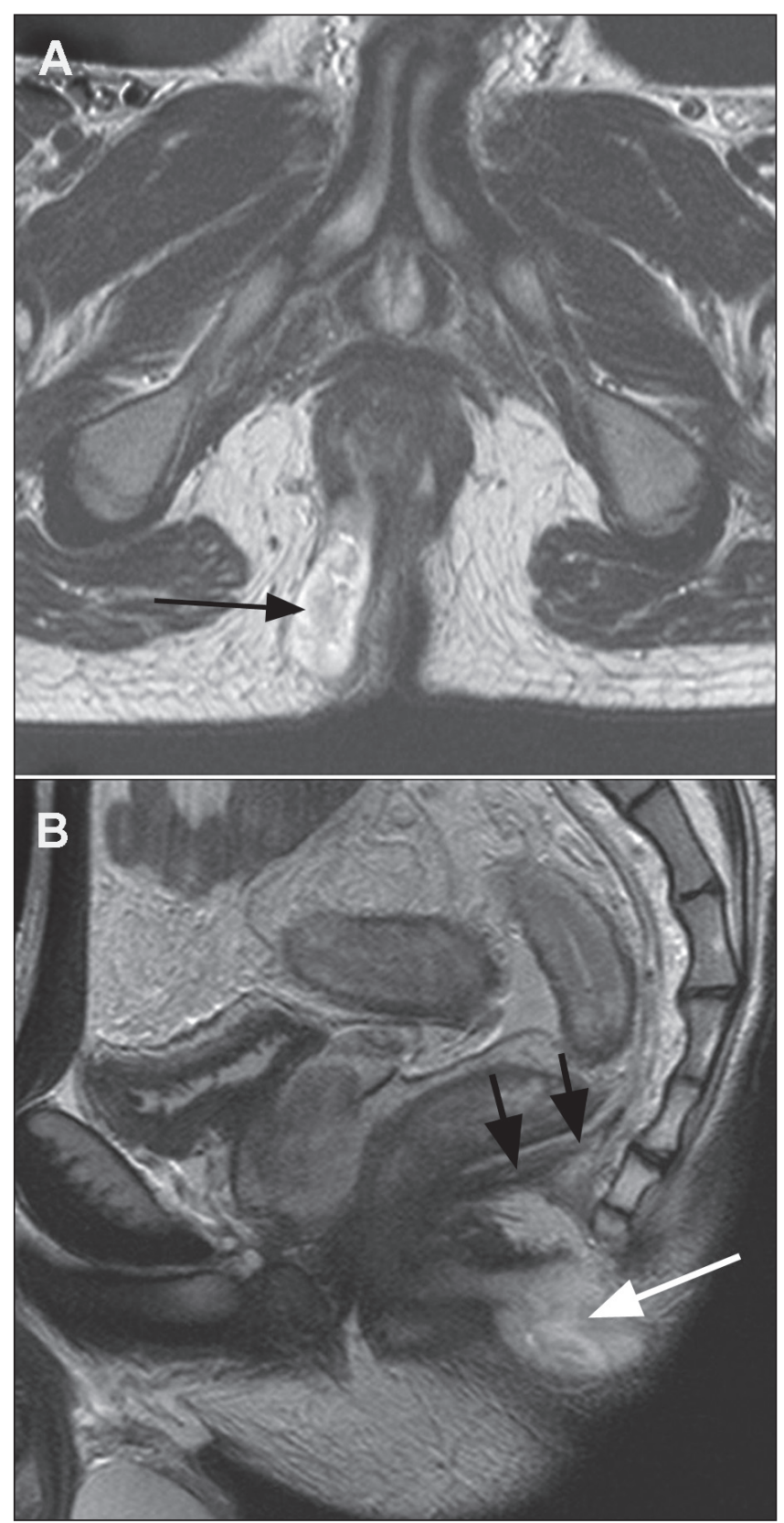

Figure 8) A Axial T2 image showing abscess collection below levator ani in the ischio anal space (arrow). B Sagittal image demonstrates the posterior extension under the coccyx (white arrow) below levator diaphragm (black arrows)

MRI is also valuable in following medical treatment, monitoring the response to treatment of inflammation and abscess collections. Reduction in the amount of contrast enhancement has been correlated with clinical improvement (14).

\section{SUMMARY}

Dedicated high-resolution MRI of the perineum is the imaging modality of choice for diagnosis and delineation of perineal IBD and its complications including fistulas, sinus tracts and abscess formation. Furthermore, MRI is a valuable tool to monitor medical treatment and is associated with a reduction in postsurgical recurrence rates when operative planning is based on MRI findings.

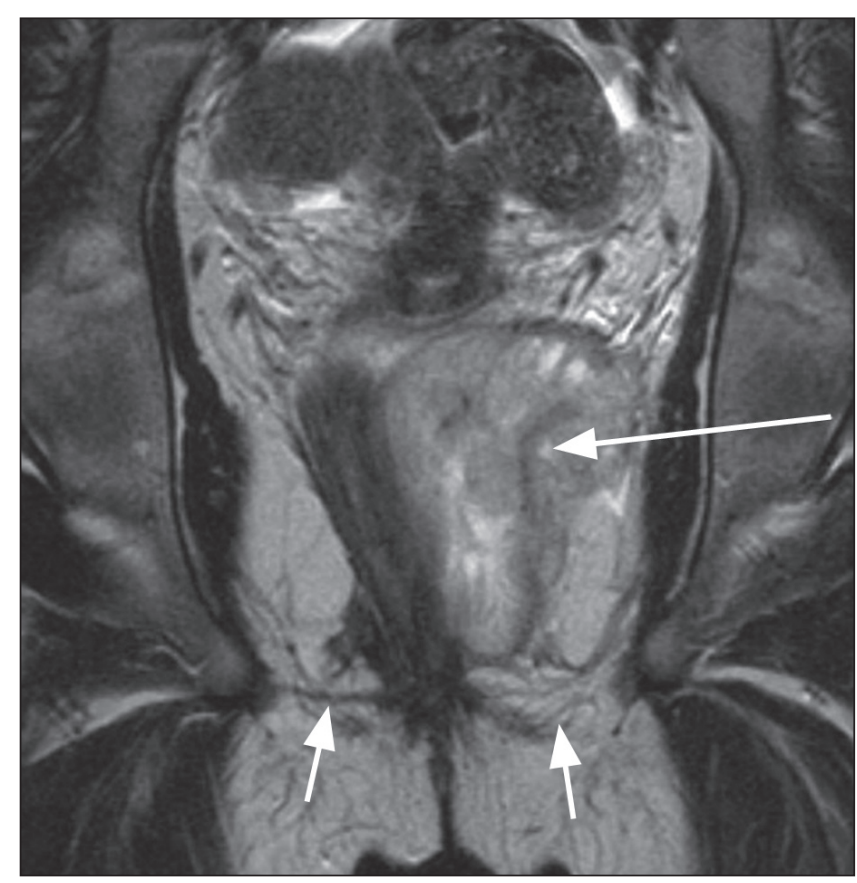

Figure 9) Coronal T2 image demonstrates large abscess collection (long arrow) above the levator ani (short arrows) in the ischio rectal space

\section{REFERENCES}

1. Paolantonio P, Ferrari R, Vecchietti F, Cucchiara S, Laghi A. Current status of MR imaging in the evaluation of IBD in a pediatric population of patients. Eur J Radiol 2009;69:418-24.

2. Chalian M, Ozturk A, Olivia-Hemker M, Huisman TAGM. MR enterography findings of inflammatory bowel disease in pediatric patients. AJR Am J Roentgenol 2011;196:W810-W816.

3. Sauer CG, Kugathasan S, Martin DR, Applegate KE. Medical radiation exposure in children with inflammatory bowel disease estimates high cumulative doses. Inflamm Bowel Dis 2011;17:2326-32.

4. Furukawa A, Saotome T, Yamasaki M, et al. Cross-sectional imaging in Crohn disease. Radiographics 2004;24:689-702.

5. Sauer CG, Middelton JP, Alazraki A, et al. Comparison of magnetic resonance enterography with endoscopy, histopathology, and laboratory evaluation in pediatric Crohn disease. J Pediatr Gasstroenterol Nutr 2012;56:178-84.

6. Van Limbergen J, Russell RK, Drummond HE, et al. Definition of phenotypic characteristic of childhood-onset inflammatory bowel disease. Gastroenterology 2008;135:1114-22.

7. Vernier-Massouille G, Balde M, Salleron J, et al. Natural history of pediatric Crohn's disease: A population-based cohort study. Gastroenterology 2008;135:1106-13.

8. Guariso G, Gasparetto M, Visona Dall Pozza L, et al. Inflammatory bowel disease developing in pediatric and adult age. J Pediatr Gastroenterol Nutr 2010;51:698-707.

9. Wise PE, Schwartz DA. The evaluation and treatment of Crohn perianal fistulae: EUA, EUS, MRI and other imaging modalities. Gastroenterol Clin North Am 2012;41:379-91.

10. Ziech M, Felt-Bersma R, Stoker J. Imaging of perianal fistulas. Clin Gastroenterol Hepatol 2009;7:1037-45.

11. Halligan S, Stoker J. Imaging of fistula in ano. Radiology 2006;239:18-33.

12. Kashyap P, Bates N. Magnetic resonance imaging anatomy of the anal canal. Austalasian Radiol 2004;48:443-9.

13. Buchanan G, Halligan S, Williams A, et al. Effect of MRI on clinical outcome of recurrent fistula-in-ano. Lancet 2002;360:1661-2.

14. Savoye-Collet C, Savoye G, Koning E, Dacher JN, Lerebours E. Fistulizing perianal Crohn's disease: Contrast enhanced magnetic resonance imaging assessment at 1 year on maintenance anti TNF alpha therapy. Inflamm Bowel Dis 2911;17:1751-8. 


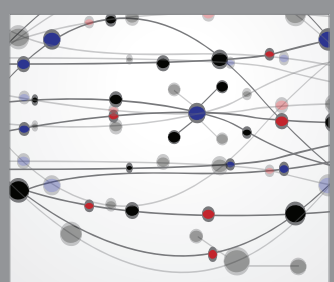

The Scientific World Journal
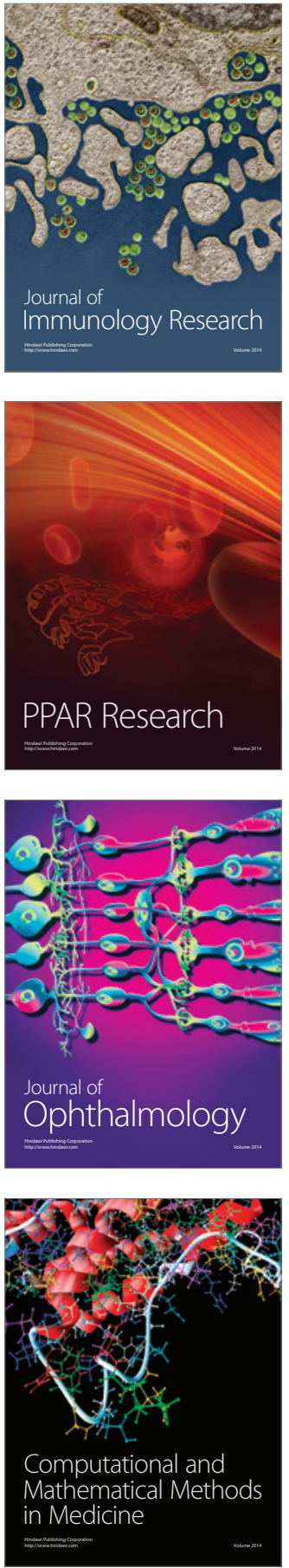

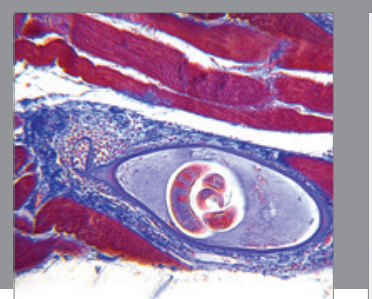

Gastroenterology Research and Practice

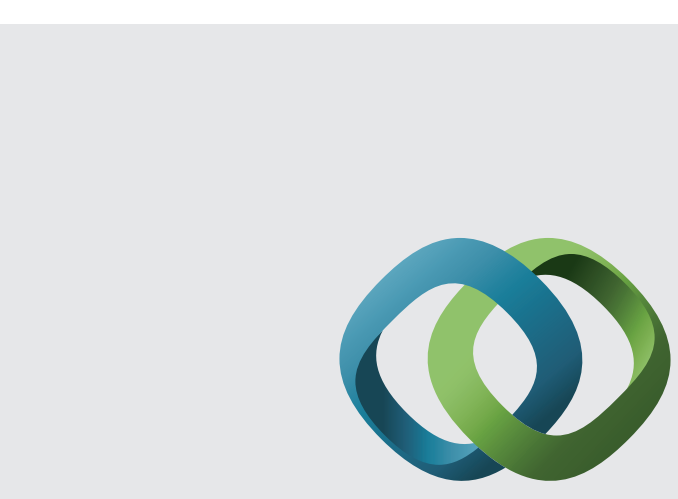

\section{Hindawi}

Submit your manuscripts at

http://www.hindawi.com
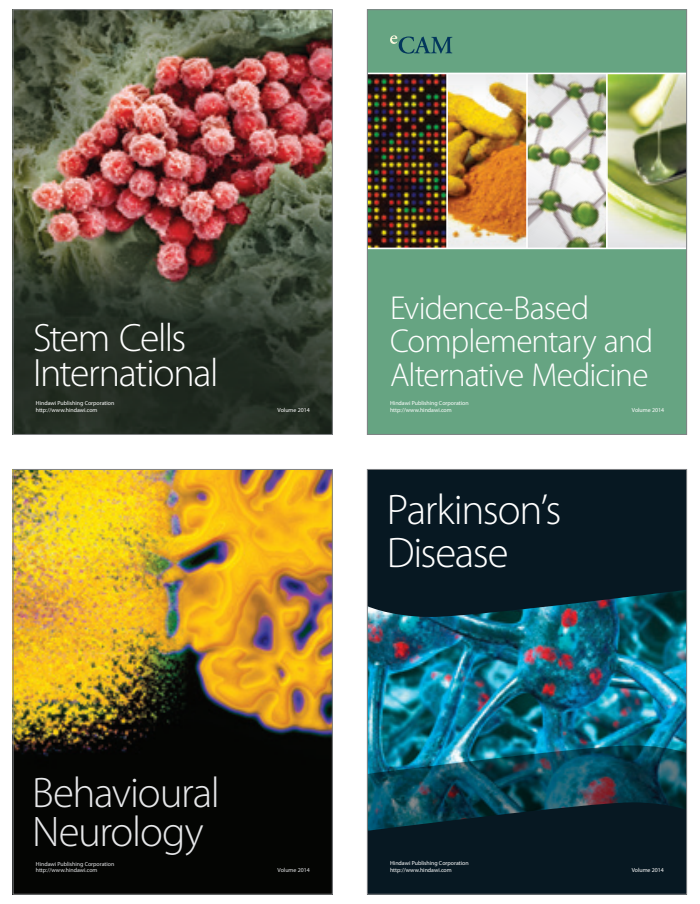
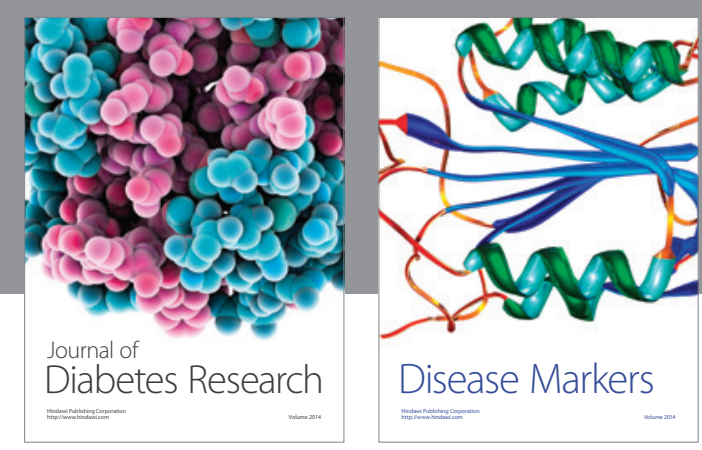

Disease Markers
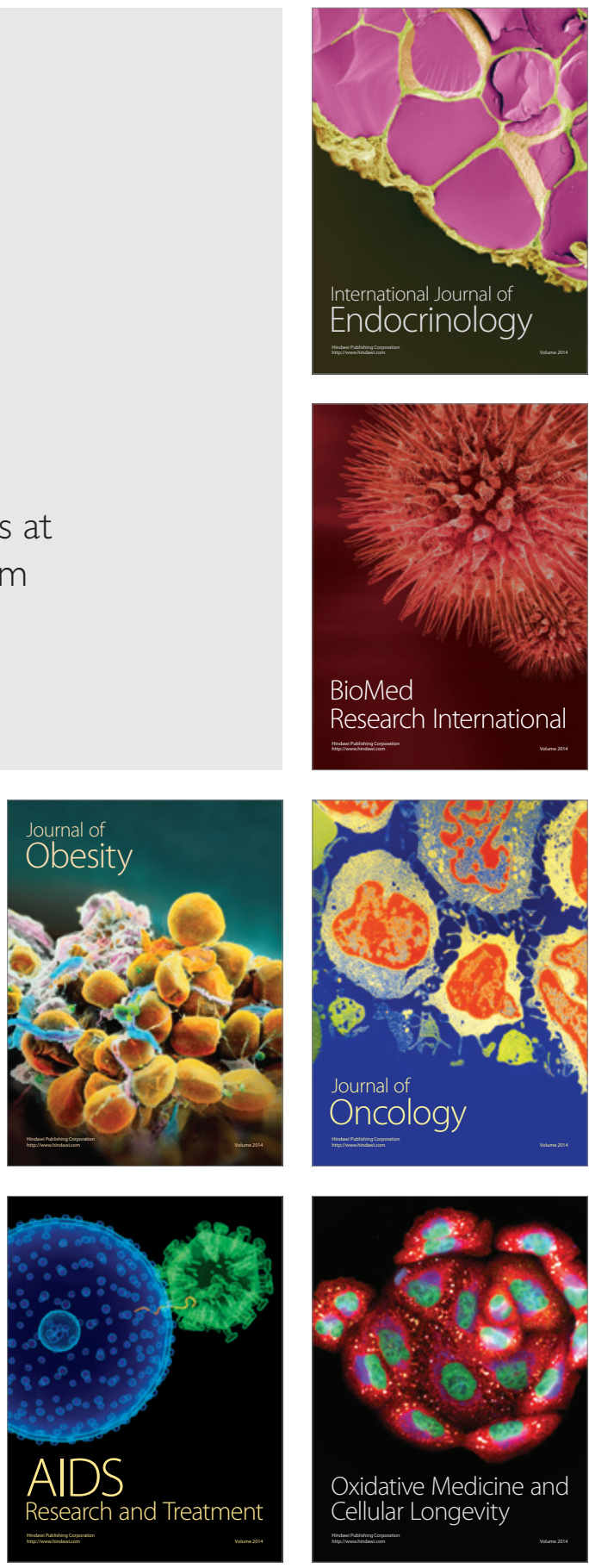